\title{
Calculated Vibrational Properties of Ubisemiquinones
}

\author{
Hari P. Lamichhane and Gary Hastings \\ Department of Physics and Astronomy, Georgia State University, 29 Peachtree Center Avenue, Atlanta, GA 30303, USA \\ Correspondence should be addressed to Gary Hastings; ghastings@gsu.edu
}

Received 15 October 2012; Accepted 27 November 2012

Academic Editor: Philip Crooke

Copyright (C) 2013 H. P. Lamichhane and G. Hastings. This is an open access article distributed under the Creative Commons Attribution License, which permits unrestricted use, distribution, and reproduction in any medium, provided the original work is properly cited.

\begin{abstract}
Density functional theory has been used to calculate harmonic normal mode vibrational frequencies for unlabeled and isotopelabeled ubisemiquinones in both the gas phase and in several solvents. It is shown that four methoxy group conformations are likely to be present in solution at room temperature. Boltzmann weighted infrared and Raman spectra for the four conformers were calculated, and composite spectra that are the sum of the Boltzmann weighted spectra were produced. These composite spectra were compared to experimental FTIR and resonance Raman spectra, and it is shown that the calculated band frequencies, relative band intensities, and ${ }^{13} \mathrm{C}$ and ${ }^{18} \mathrm{O}$ isotope-induced band shifts are in excellent agreement with experiment. The calculations show that the $\mathrm{C}=\mathrm{O}$ and $\mathrm{C}=\mathrm{C}$ modes of ubisemiquinone strongly mix with methoxy methyl $\mathrm{CH}$ bending vibrations, and that the degree of mixing is altered upon isotope labeling, resulting in complicated changes in mode frequencies, intensities, and composition upon isotope labeling. Upon consideration of the calculated potential energy distributions of the normal modes of ubisemiquinone, and how they change upon isotope labeling, an explanation of some puzzling features in previously published Raman spectra is provided.
\end{abstract}

\section{Introduction}

Ubiquinones ( $\mathrm{UQ}_{n}$ : 2,3-dimethoxy-5-methyl-6-polyprenyl1,4-benzoquinones) play an important role in biological electron and proton transfer processes that occur in both respiration and photosynthesis [1]. In photosynthetic reaction centers from purple bacteria, two UQ molecules, called $\mathrm{Q}_{\mathrm{A}}$ and $\mathrm{Q}_{\mathrm{B}}$, act as terminal electron acceptors [2]. In purple bacterial reaction centers (PBRCs) (see Abbreviations) from Rhodobacter $\left(R b\right.$.) sphaeroides, $\mathrm{Q}_{\mathrm{A}}$ and $\mathrm{Q}_{\mathrm{B}}$ are both ubiquinone-10 $\left(\mathrm{UQ}_{10}\right)$ molecules. $\mathrm{Q}_{\mathrm{A}}$ and $\mathrm{Q}_{\mathrm{B}}$ have very different functions; however, $Q_{A}$ is an intermediary cofactor involved in transferring electrons from bacteriopheophytin to $Q_{B}$, while $Q_{B}$ couples electron and proton transfer processes $[3,4]$. The very different redox functions of $Q_{A}$ and $Q_{B}$ are testimony to the flexibility of UQs in biological processes. Since $\mathrm{Q}_{\mathrm{A}}$ and $\mathrm{Q}_{\mathrm{B}}$ are both $\mathrm{UQ}_{10}$ molecules, pigment-protein interactions must modulate the functional properties of $\mathrm{UQ}_{10}$ in PBRCs. Elucidation of these pigment-protein interactions is at the heart of much current research in photosynthesis $[5,6]$.
Fourier transform infrared (FTIR) difference spectroscopy (DS) is a sensitive molecular-level probe of pigmentprotein interactions, and it is widely used to study both the neutral and reduced states of the quinones occupying the $\mathrm{Q}_{\mathrm{A}}$ and $\mathrm{Q}_{\mathrm{B}}$ binding sites in PBRCs [7]. Although $\mathrm{Q}_{\mathrm{A}}{ }^{-} / \mathrm{Q}_{\mathrm{A}}$ and $\mathrm{Q}_{\mathrm{B}}{ }^{-} / \mathrm{Q}_{\mathrm{B}}$ FTIR difference spectra have been obtained under a wide range of conditions for variously treated PBRC's, these spectra continue to be difficult to interpret because many bands not associated with the quinone also contribute to the spectra. Reconstitution of PBRCs with isotopically labeled quinones, however, has allowed some separation of the contributions of the quinones from those of the protein to the spectra [7]. Nonetheless the hypothesized band assignments in the experimental spectra, particularly those assignments associated with the ubiquinone anion radical, are still ambiguous and have not been modeled computationally.

One basis for developing an understanding of bands in $\mathrm{Q}_{\mathrm{A}}{ }^{-} / \mathrm{Q}_{\mathrm{A}}$ and $\mathrm{Q}_{\mathrm{B}}{ }^{-} / \mathrm{Q}_{\mathrm{B}}$ FTIR DS is to first consider spectra of the relevant quinones in solution. Infrared (IR) absorption spectra [8,9] and resonance Raman spectra [10] for 
ubisemiquinones in solution have been obtained. However, from a computational standpoint, even these simpler solution spectra are poorly understood. The work outlined in this paper is aimed at addressing this problem.

Few computational studies aimed at modeling the vibrational properties of ubisemiquinones (UQ ${ }^{-}$) have been undertaken. The work that has been undertaken $[11,12]$ is limited in one way or another; for example, tail-less quinone models in only the gas phase were considered, using relatively low levels of theory. Previously it was claimed that the calculated normal modes and associated isotope-induced frequency shifts are in good agreement with experiment [12]. Isotope shifts do appear to agree with experiment. However, upon careful examination, it appears that the previously calculated normal modes (frequencies and intensities) are not in agreement with experimental spectra (see below). In the light of this finding we have used more robust computational methods to investigate the vibrational properties of ubisemiquinones in the gas phase and in solution.

In this paper we describe the simulation of FTIR and Raman spectra associated with labeled and unlabeled tailcontaining ubisemiquinones in both the gas phase and in solvent.

\section{Materials and Methods}

2.1. Calculations. Molecular geometry optimizations and harmonic vibrational frequency calculations were performed using hybrid density functional theory (DFT) methods, employing the B3LYP functional and the 6-31 + G(d) basis set within Gaussian 03 [13]. 6-31 + G(d) is preferable to $6-31 \mathrm{G}(\mathrm{d})$ for calculations involving semiquinones [14]. For calculations including solvent, the integral equation formalism (IEF) [15-17] of the polarizable continuum model (PCM) $[18,19]$ was used. The PCM uses the united atom cavity approach. Cavity parameters used were $\mathrm{OFac}=0.89$ (overlap index between interlocking spheres) and $R_{\text {Min }}=0.2$ (minimum radius in Angstroms for overlapping spheres). Very similar spectra were calculated when a smaller number of added spheres were considered $\left(\mathrm{OFac}=0.8\right.$ and $R_{\text {Min }}=$ 0.5 ). The potential energy distribution (PED) (or total energy distribution) of normal modes was calculated using gar2ped [20].

Calculated normal mode vibrational frequencies presented here were scaled by 0.9808 . Such a scale factor is standard for calculations using the specified functional and basis set and was derived by comparing the frequencies of bands in experimental and calculated spectra. Such a scaling of the calculated frequencies is undertaken only to facilitate a comparison between calculated and experimental spectra. We are primarily interested in vibrational frequency changes that occur upon isotope labeling, and these frequency differences are accurately calculated without scaling [14, 21].

\section{Results}

3.1. UQ Structure and Numbering. Figure 1 shows a geometry-optimized $\mathrm{UQ}_{1}{ }^{-}$model with the atom numbering scheme displayed. UQ has two carbonyl groups $\left(\mathrm{C}_{1}=\mathrm{O}_{18}\right.$ and $\left.\mathrm{C}_{4}=\mathrm{O}_{15}\right)$, two methoxy groups $\left(\mathrm{C}_{3}-\mathrm{O}_{16}-\mathrm{CH}_{3}\right.$ and $\mathrm{C}_{2}-\mathrm{O}_{17}-\mathrm{CH}_{3}$ ), a methyl group at $\mathrm{C}_{5}$, and an isoprene unit at $\mathrm{C}_{6}$. In our calculations we used UQ models with only a single isoprene unit. As outlined previously [21], the calculated vibrational properties of $\mathrm{UQ}_{1}$ ( or $\mathrm{UQ}_{1}{ }^{-}$) are very similar to that found for $\mathrm{UQ}_{n}$ (with $n>1$ ). Also shown in Figure 1 are relevant internal coordinates of $\mathrm{UQ}_{1}{ }^{-}$. The normal modes will be expressed in terms of contributions from these internal coordinates. Of particular interest in this paper are the coordinates $\mathrm{R} 3, \mathrm{R} 9, \mathrm{R} 4$, and $\mathrm{R} 10$ which are due to $\mathrm{C}_{1} \ldots \mathrm{O}, \mathrm{C}_{4} \ldots \mathrm{O}, \mathrm{C}_{2} \ldots \mathrm{C}_{3}$, and $\mathrm{C}_{5} \ldots \mathrm{C}_{6}$ stretching vibrations, respectively. The methoxy methyl $\mathrm{CH}$ bending vibrations (coordinates $\delta \mathrm{C} 8$ and $\delta \mathrm{C} 9$ ) are also of considerable relevance in this paper, as they strongly couple to the $\mathrm{C}$... O vibrations (see below). This was not found to occur for neutral UQ [21].

3.2. Calculated Structure of Ubisemiquinone ${ }_{1}\left(U Q_{1}{ }^{-}\right)$. Previously we showed that neutral $\mathrm{UQ}_{1}$ can adopt at least eight different methoxy group conformations at room temperature [21]. To establish which conformations may be present for $\mathrm{UQ}_{1}{ }^{-}$, single-point energy calculations were undertaken for methoxy group dihedral angles that were stepped in $10^{\circ}$ increments. That is, $36 \times 36$ structures with fixed methoxy group dihedral angles were geometry optimized.

A contour plot of energy versus the $\mathrm{C}_{2}$ and $\mathrm{C}_{3}$ dihedral angles is shown in Figure 2, which indicates that there are four low-energy $\mathrm{UQ}_{1}{ }^{-}$conformations, each with $\mathrm{C}_{2}$ and $\mathrm{C}_{3}$ dihedral angles close to $\pm 120^{\circ}$. The four conformers are labeled A, B, E, and F in Figure 2. These four conformers are similar to the neutral $\mathrm{UQ}_{1}$ conformers labeled J, L, I, and $\mathrm{K}$, respectively, that were described previously [21].

Following single-point energy calculations, the four $\mathrm{UQ}_{1}{ }^{-}$conformations were further geometry optimized (energy minimized) without constraining the dihedral angles. Calculations were undertaken for the four conformations in the gas phase and in several solvents that have dielectric constants spanning a wide range (2.2-78).

Calculated bond lengths, the $\mathrm{C}_{6}-\mathrm{C}_{10}-\mathrm{C}_{11}$ bond angle, and methoxy group dihedral angles for the various $\mathrm{UQ}_{1}{ }^{-}$ conformers in the gas phase and $\mathrm{CCl}_{4}$ are listed in Table 1. Similar trends in the listed data are calculated for the conformers in other solvents (data not shown). Data for $\mathrm{UQ}_{10} / \mathrm{UQ}_{10}{ }^{-}$in the $\mathrm{Q}_{\mathrm{A}} / \mathrm{Q}_{\mathrm{B}}$ binding site is also listed in Table 1 .

The data presented in Table 1 demonstrates that all four conformers in solvent are within $0.45 \mathrm{kcal} / \mathrm{mol}$ in energy $(k T$ at $298 \mathrm{~K}$ is $\sim 0.59 \mathrm{kcal} / \mathrm{mol}$ ), so all four conformers would be expected to be present to some degree in solvent at room temperature. The orientation of the methoxy groups of the four geometry-optimized conformers (in $\mathrm{CCl}_{4}$ ) as well as the calculated dihedral angles are shown in the insets in Figure 2. The corresponding dihedral angles for the four conformers in different solvents are similar (data not shown).

The hydrocarbon chain (isoprene unit) attached at $\mathrm{C}_{6}$ makes a distinct kink at $\mathrm{C}_{10}$. The $\mathrm{C}_{6}-\mathrm{C}_{10}-\mathrm{C}_{11}$ angle is close to $113^{\circ}$ for all four conformers (Table 1). This angle is also 


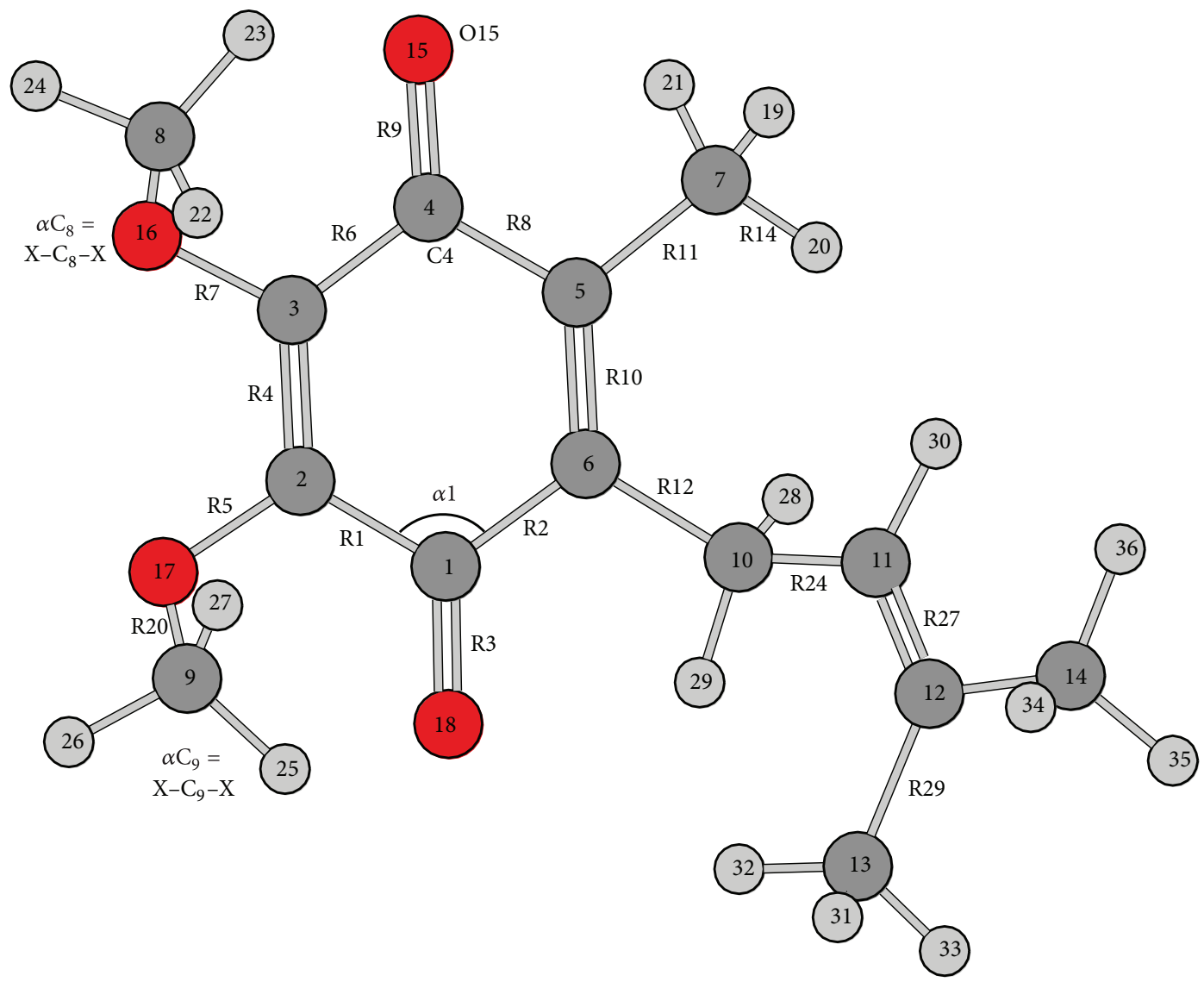

FIGURE 1: Structure and atomic numbering scheme for an optimized $\mathrm{UQ}_{1}{ }^{-}$model. Various internal coordinates are also outlined. $\mathrm{R}$ represents bond stretching, $\alpha$ represents a bending of the angle between two bonds, and $\delta$ represents a combination of angle bending centered at a vertex atom. For example, R4 represents a $\mathrm{C}_{2}=\mathrm{C}_{3}$ stretching vibration, $\alpha 1$ represents a bending of the angle between the $\mathrm{C}_{1}=\mathrm{C}_{2}$ and $\mathrm{C}_{1}=\mathrm{C}_{6}$ bonds, and $\delta \mathrm{C} 8$ represents a bending vibration of the three $\mathrm{C}_{8}-\mathrm{H}$ groups.

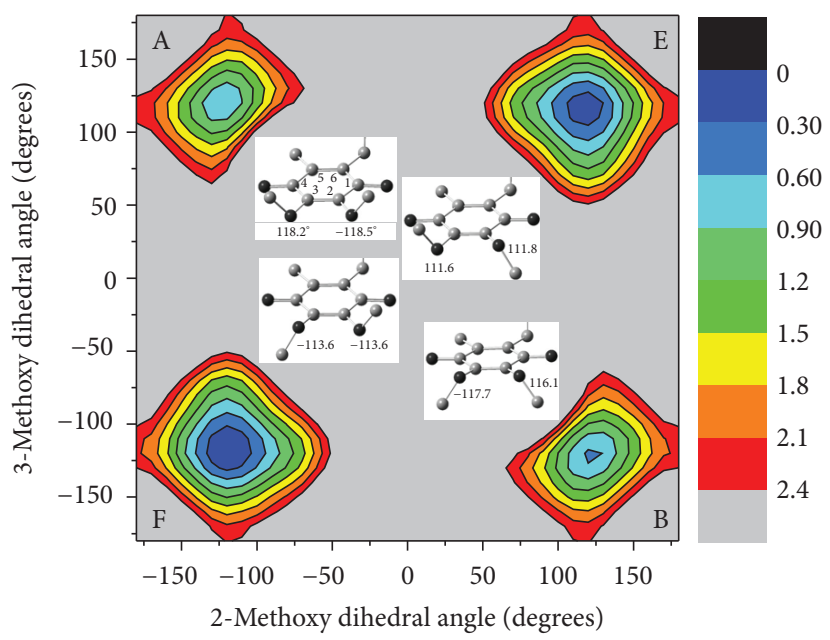

FIgURE 2: Calculated optimized energy (in kcal/mol) of $\mathrm{UQ}_{1}{ }^{-}$for all $\mathrm{C}_{2}\left(\mathrm{C}_{3}-\mathrm{C}_{2}-\mathrm{O}_{17}-\mathrm{C}_{9}\right)$ and $\mathrm{C}_{3}\left(\mathrm{C}_{4}-\mathrm{C}_{3}-\mathrm{O}_{16}-\mathrm{C}_{8}\right)$ dihedral angles. The energy axis was shifted so that the lowest energy conformer was set to zero. The insets show the structures of the four optimized methoxy group conformers (obtained for calculations in $\mathrm{CCl}_{4}$ ). The emphasis is on displaying the methoxy group orientations, so hydrogen atoms have been removed and the tail at $\mathrm{C}_{6}$ is not shown. Oxygen/carbon atoms are dark/light shade, respectively. $\mathrm{C}_{2}$ and $\mathrm{C}_{3}$ dihedral angles are also listed in each of the insets. 
TABLE 1: Calculated bond lengths (in $\AA$ ) and bond angles (in degrees) for all $\mathrm{UQ}_{1}{ }^{-}$conformers in the gas phase and $\mathrm{CCl}_{4}$. Calculated methoxy group dihedral angles and relative energies (in $\mathrm{kcal} / \mathrm{mol}$ ) for all conformers are also listed. The lowest energy conformer is set to zero and the energies of $\mathrm{UQ}_{1}{ }^{-}$conformers relative to this zero are listed $(k T$ at $298 \mathrm{~K}$ is $\sim 0.59 \mathrm{kcal} / \mathrm{mol})$. Bond lengths and angles for neutral $\mathrm{UQ}_{10}$ in the $\mathrm{Q}_{\mathrm{A}}$ binding site (PDB file: $1 \mathrm{AI}$ ) and $\mathrm{UQ}_{10}{ }^{-}$in the $\mathrm{Q}_{\mathrm{B}}$ binding site (PDB file: $1 \mathrm{AIG}$ ) are also listed.

\begin{tabular}{|c|c|c|c|c|c|c|c|c|c|c|}
\hline & \multicolumn{4}{|c|}{$\mathrm{UQ}_{1}{ }^{-}$in gas phase } & \multicolumn{4}{|c|}{$\mathrm{UQ}_{1}{ }^{-}$in $\mathrm{CCl}_{4}$} & \multirow{2}{*}{$\mathrm{Q}_{\mathrm{A}}$} & \multirow{2}{*}{$\mathrm{Q}_{\mathrm{B}}$} \\
\hline & A & B & E & $\mathrm{F}$ & A & $\mathrm{B}$ & E & $\mathrm{F}$ & & \\
\hline $\mathrm{C}_{1} \ldots \mathrm{O}$ & 1.273 & 1.273 & 1.273 & 1.273 & 1.274 & 1.274 & 1.273 & 1.273 & 1.234 & 1.227 \\
\hline $\mathrm{C}_{4} \ldots \mathrm{O}$ & 1.272 & 1.272 & 1.271 & 1.271 & 1.247 & 1.274 & 1.274 & 1.274 & 1.232 & 1.221 \\
\hline $\mathrm{C}_{2} \ldots \mathrm{C}_{3}$ & 1.380 & 1.380 & 1.379 & 1.379 & 1.380 & 1.379 & 1.378 & 1.379 & 1.404 & 1.379 \\
\hline $\mathrm{C}_{5} \cdots \mathrm{C}_{6}$ & 1.384 & 1.384 & 1.384 & 1.384 & 1.384 & 1.385 & 1.385 & 1.385 & 1.419 & 1.398 \\
\hline $\mathrm{C}_{6}-\mathrm{C}_{10}-\mathrm{C}_{11}$ & 113.4 & 113.5 & 113.5 & 113.5 & 113.3 & 113.2 & 113.3 & 113.2 & 113.0 & 111.0 \\
\hline $\mathrm{C}_{3}-\mathrm{C}_{2}-\mathrm{O}-\mathrm{CH}_{3}$ & -121.8 & 120.8 & 116.7 & -117.3 & -118.5 & 116.1 & 111.8 & -113.6 & -57.1 & 79.9 \\
\hline $\mathrm{C}_{2}-\mathrm{C}_{3}-\mathrm{O}-\mathrm{CH}_{3}$ & 122.4 & -123.2 & 118.3 & -119.0 & 118.2 & -117.7 & 111.6 & -113.6 & 109.5 & -121.3 \\
\hline$\Delta E$ & 0.537 & 0.646 & 0.106 & 0 & 0.450 & 0.387 & 0.002 & 0 & & \\
\hline
\end{tabular}

similar to that found for $\mathrm{UQ}_{10} / \mathrm{UQ}_{10}{ }^{-}$occupying the $\mathrm{Q}_{\mathrm{A}} / \mathrm{Q}_{\mathrm{B}}$ binding site, respectively (Table 1).

3.3. Calculated Vibrational Frequencies of $U_{Q_{1}}{ }^{-}$. Figure 3(a) shows calculated IR spectra for the four $\mathrm{UQ}_{1}{ }^{-}$conformers in $\mathrm{CCl}_{4}$, in the $1530-1425 \mathrm{~cm}^{-1}$ region. This spectral region is chosen because it is the region where the main $\mathrm{C} \cdots \mathrm{O}$ and $\mathrm{C} \ldots \mathrm{C}$ modes of $\mathrm{UQ}^{-}$lie, and it is therefore the region generally focused upon in FTIR studies of UQ ${ }^{-}$in solution [8-10]. The spectra of the conformers in Figure 3(a) have been scaled by the appropriate Boltzmann factors, which were calculated based on the relative energies of the four conformations (Table 1). A composite spectrum which is the sum of the four Boltzmann weighted spectra is also shown in Figure 3(a). The corresponding calculated composite spectra for $\mathrm{UQ}^{-}$in various solvents are presented in Figures 3(b) and $3(\mathrm{c})$.

In the composite spectra an intense band is observed at $1500-1478 \mathrm{~cm}^{-1}$, depending on the solvent. The frequency of this absorption band decreases, and the intensity increases, as the dielectric constant of the solvent increases. The frequency changes as a function of dielectric constant are outlined in the inset in Figure 3(a), which demonstrates that the band frequency is strongly solvent dependant only for solvents with dielectric constant ranging from $\sim 1$ to 20 . Similar results have been found for PCM calculations of small neutral ketones in nonprotic solvents [22].

The calculated composite spectrum for $\mathrm{UQ}_{1}{ }^{-}$in $\mathrm{CCl}_{4}$ (Figure 3(a)) displays an intense band at $1493 \mathrm{~cm}^{-1}$. Lower intensity peaks are observed at 1483 and $1450 \mathrm{~cm}^{-1}$. Table 2(b) lists the frequencies, IR intensities, Raman activities, and potential energy distributions for the normal modes that contribute to the bands in the spectra of $\mathrm{UQ}_{1 \mathrm{~F}}{ }^{-}$in $\mathrm{CCl}_{4}$. Similar results are calculated for conformers A, B, and E (data not shown), as would be expected given the similarity in the spectra of the conformers in Figure 3(a). For comparison, Table 2(a) also lists data for $\mathrm{UQ}_{1 \mathrm{~F}}{ }^{-}$in the gas phase.

For $\mathrm{UQ}_{1}{ }^{-}$in $\mathrm{CCl}_{4}$, the band at $1493 \mathrm{~cm}^{-1}$ (Figure 3(a)) is due to two intense normal modes at $\sim 1491$ and $\sim 1495 \mathrm{~cm}^{-1}$.
The $1491 \mathrm{~cm}^{-1}$ normal mode is due predominantly to $\mathrm{C}_{4} \ldots \mathrm{O}$ stretching [R9(56\%)] while the $1491 \mathrm{~cm}^{-1}$ normal mode is due predominantly to $\mathrm{C}_{1} \ldots \mathrm{O}$ stretching [R3(46\%)]. For all four conformers, the $\mathrm{C}_{1} \cdots \mathrm{O}$ and $\mathrm{C}_{4} \ldots \mathrm{O}$ groups vibrate separately at a similar frequency with similar intensity. This is also observed for $\mathrm{UQ}_{1}{ }^{-}$in other solvents (not shown). This behavior is different from that found in calculations for neutral $\mathrm{UQ}_{1}$, however, where most of the intensity is in only one of the $\mathrm{C}=\mathrm{O}$ modes [21].

For $\mathrm{UQ}_{1}{ }^{-}$in the gas phase the most intense band is calculated at $1500 \mathrm{~cm}^{-1}$. In gas phase calculations, however, this band is due to the out-of-phase vibration of both C...O groups [R3(29\%)-R9(27\%)] (Table 2(a)). In gas phase calculations, the in-phase vibration of both $\mathrm{C} \ldots \mathrm{O}$ groups is found at $1495 \mathrm{~cm}^{-1}$, and it is approximately a factor of seven lower in intensity than the out-of-phase $\mathrm{C}$... O vibration (Table 2(a)). In gas phase calculations the in-phase $\mathrm{C}$... $\mathrm{O}$ vibration is very strongly Raman active while the out-ofphase $\mathrm{C} . . \mathrm{O}$ vibration is not. In contrast, for calculations in $\mathrm{CCl}_{4}$, both the $\mathrm{C}_{1} \ldots \mathrm{O}$ and $\mathrm{C}_{4} \ldots \mathrm{O}$ vibrations are strongly Raman active.

In all spectra in Figure 3 a weak band is found at $1522 \mathrm{~cm}^{-1}$. This band is due to an out-of-phase vibration of the $\mathrm{C} \cdots \mathrm{C}$ groups of the quinone ring (R4-R10). Given the antisymmetric nature of the vibration it is very weakly Raman active. The in-phase vibration of the C...C groups of the quinone ring occurs at $1607 \mathrm{~cm}^{-1}$ and is IR silent but very strongly Raman active (Table 2).

A relatively intense band is found at $1450-1456 \mathrm{~cm}^{-1}$ in all of the spectra in Figure 3. This band is due predominantly to $\mathrm{CH}$ bending vibrations of both methoxy methyl groups ( $\delta \mathrm{C} 8$ and $\delta \mathrm{C} 9)$ (Table 2(b)). Given that the mode is due to $\mathrm{CH}$ bending vibrations of the methoxy methyl groups it is not surprising that the precise frequency of this normal mode can vary by as much as $5 \mathrm{~cm}^{-1}$ among the four conformers (Figure 3(a)).

The calculated spectra of the four $\mathrm{UQ}_{1}{ }^{-}$conformers are similar (Figure 3(a)). We also find that the spectra are very similar for isotope-labeled versions of the conformers (not 


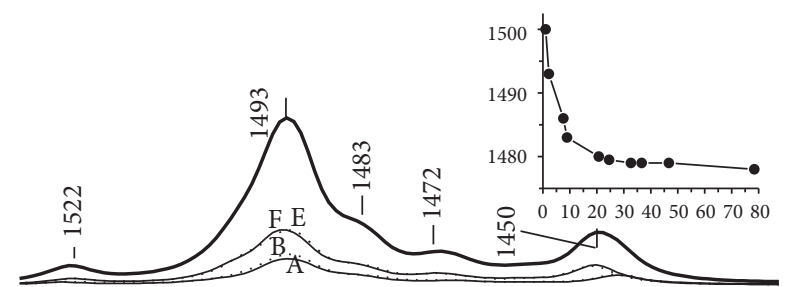

(a)
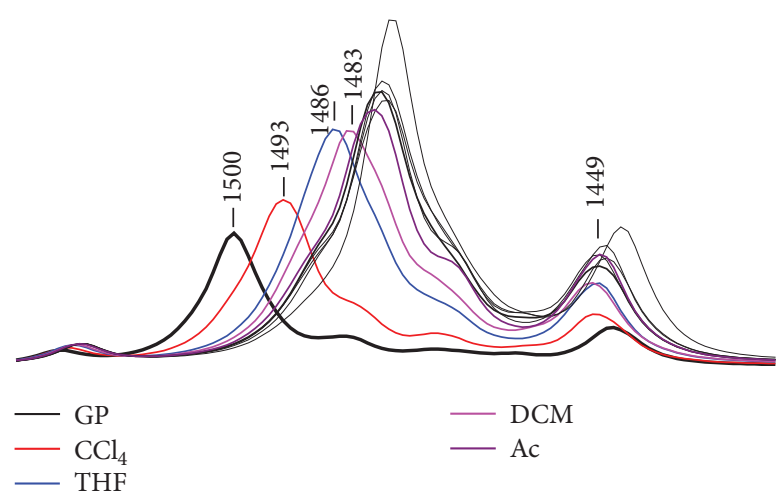

(b)

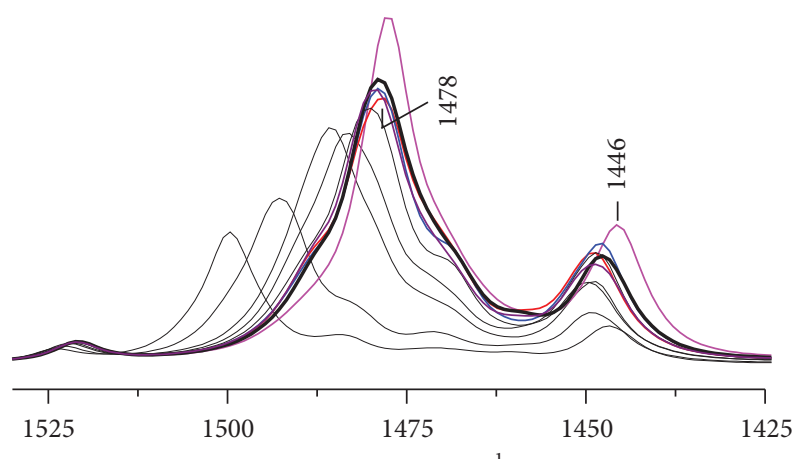

$-\mathrm{Et}$ Wavenumber $\left(\mathrm{cm}^{-1}\right)$

$-\mathrm{MeCN}$

(c)

FIGURE 3: (a) Calculated Boltzmann weighted IR spectra for the four $\mathrm{UQ}_{1}{ }^{-}$conformations in $\mathrm{CCl}_{4}$ : $\mathrm{UQ}_{1 \mathrm{~A}}{ }^{-}$and $\mathrm{UQ}_{1 \mathrm{E}}{ }^{-}$(dotted), $\mathrm{UQ}_{1 \mathrm{~B}}{ }^{-}$and $\mathrm{UQ}_{1 \mathrm{~F}}{ }^{-}$(solid). A composite spectrum that is the sum of the Boltzmann weighted spectra is also shown (thick line). (b) Calculated composite IR spectra for $\mathrm{UQ}_{1}{ }^{-}$in the gas phase (black), $\mathrm{CCl}_{4}$ (red), THF (blue), DCM (magenta), and acetone (purple). (c) Calculated composite IR spectra for $\mathrm{UQ}_{1}{ }^{-}$in ethanol (purple), methanol (black), MeCN (red), DMSO (blue), and $\mathrm{H}_{2} \mathrm{O}$ (magenta). The spectra displayed with thin lines in $\mathrm{B} / \mathrm{C}$ are the spectra from $\mathrm{C} / \mathrm{B}$, respectively. All frequencies were scaled by 0.9808 . Inset: graph of peak frequency as a function of solvent dielectric constant. Dielectric constants for $\mathrm{CCl}_{4}$, THF, DCM, acetone, ethanol, methanol, acetonitryl, DMSO, and $\mathrm{H}_{2} \mathrm{O}$ are 2.23, 7.58, 8.93, 20.7, 24.3, 32.63, $36.64,46.7$, and 78.39 , respectively. shown). For this reason we will consider only the Boltzmann weighted composite spectra below. In addition, we will consider spectra for $\mathrm{UQ}_{1}{ }^{-}$in $\mathrm{CCl}_{4}$, noting that similar results and conclusions hold for $\mathrm{UQ}_{1}{ }^{-}$in other solvents.

Figure 4 shows calculated IR (left) and Raman (right) spectra for unlabeled, ${ }^{13} \mathrm{C}$, and ${ }^{18} \mathrm{O}$ isotope-labeled $\mathrm{UQ}_{1}{ }^{-}$ in the gas phase (a) and $\mathrm{CCl}_{4}$ (b). The normal modes (frequencies, intensities, Raman activities, and PEDs) that give rise to the bands in the spectra in Figure 4 are also listed in Table 2.

As discussed above, for unlabeled $\mathrm{UQ}_{1}{ }^{-}$in $\mathrm{CCl}_{4}$ the $1493 \mathrm{~cm}^{-1}$ band (IR spectrum) is due to separate $\mathrm{C}_{4} \ldots \mathrm{O}$ and $\mathrm{C}_{1} \ldots \mathrm{O}$ vibrations. Upon ${ }^{13} \mathrm{C}$ labeling the $1493 \mathrm{~cm}^{-1}$ band appears to downshift $39 \mathrm{~cm}^{-1}$ to $1454 \mathrm{~cm}^{-1}$ (Figure $4(\mathrm{~b})$ ). Such a downshift is expected for a band that is due to C...O groups. Table 2(b) indicates that the $1454 \mathrm{~cm}^{-1}$ band in the spectrum of ${ }^{13} \mathrm{C}_{\text {labeled }} \mathrm{UQ}_{1}{ }^{-}$in $\mathrm{CCl}_{4}$ is due to a $\mathrm{C}_{4} \ldots \mathrm{O}$ stretching vibration mixed with $\mathrm{CH}$ methyl bending vibrations (associated with both methoxy methyl groups). A very low-intensity normal mode at $1458 \mathrm{~cm}^{-1}$ also contributes to the $1454 \mathrm{~cm}^{-1}$ band in the IR spectrum of ${ }^{13} \mathrm{C}$-labeled $\mathrm{UQ}_{1}{ }^{-}$ in $\mathrm{CCl}_{4}$. This $1458 \mathrm{~cm}^{-1}$ mode is due to a $\mathrm{C}_{1} \ldots \mathrm{O}$ stretching vibration mixed with $\mathrm{CH}$ methoxy methyl bending vibrations (Table 2(b)). So both $\mathrm{C}$...O groups give rise to intense normal modes for unlabeled $\overline{\mathrm{UQ}_{1}}{ }^{-}$in $\mathrm{CCl}_{4}$. However, upon ${ }^{13} \mathrm{C}$ labeling, only one intense $\mathrm{C}$... O mode is found while the other is considerably weaker. Similar ${ }^{13} \mathrm{C}$ isotope-induced changes are found for calculations of $\mathrm{UQ}_{1}{ }^{-}$in the gas phase (Table 2(a)).

The band at $1449 \mathrm{~cm}^{-1}$ in the IR spectrum for unlabeled $\mathrm{UQ}_{1}{ }^{-}$in $\mathrm{CCl}_{4}$ is due predominantly to $\mathrm{CH}$ bending vibrations of both methoxy methyl groups. Upon ${ }^{13} \mathrm{C}$ labeling the $1449 \mathrm{~cm}^{-1}$ band downshifts from $18 \mathrm{~cm}^{-1}$ to $1431 \mathrm{~cm}^{-1}$ (Figure 4(b)). The $1431 \mathrm{~cm}^{-1}$ mode is due to the out-of-phase vibration of both $\mathrm{C}$...O groups $[-\mathrm{R} 3(24 \%)+\mathrm{R} 9(11 \%)]$ coupled to a $\mathrm{C}_{3}$ methoxy methyl bending vibration $[\delta \mathrm{C} 8(32 \%)]$.

Other than the normal modes just discussed, $\mathrm{C} \ldots \mathrm{O}$ stretching vibrations (R9 and R3) contribute to at least 6 other modes in the $1500-1400 \mathrm{~cm}^{-1}$ region for ${ }^{13} \mathrm{C}$-labeled $\mathrm{UQ}_{1}{ }^{-}$. Similar results are found for ${ }^{13} \mathrm{C}$-labeled $\mathrm{UQ}_{1}{ }^{-}$in the gas phase.

In the IR spectrum of unlabeled $\mathrm{UQ}_{1}{ }^{-}$in $\mathrm{CCl}_{4}$ the weak band at $1523 \mathrm{~cm}^{-1}$ is due predominantly to an out-of-phase C...C vibration (R4-R10). The in-phase C...C vibration (R4 $+\overline{\mathrm{R}} 10)$ occurs at $1607 \mathrm{~cm}^{-1}$, with negligible IR intensity but high Raman activity (Figure 4(b)). The in-phase C...C mode downshifts $57 \mathrm{~cm}^{-1}$ to $1550 \mathrm{~cm}^{-1}$ upon ${ }^{13} \mathrm{C}$ labeling with little change in the mode composition (Table 2(b)).

In the unlabeled species the relatively pure $\mathrm{C}$... O modes are found near $1493 \mathrm{~cm}^{-1}$ (in $\mathrm{CCl}_{4}$ ). Upon ${ }^{18} \mathrm{O}$ labeling these C...O modes are expected to downshift from $\sim 40 \mathrm{~cm}^{-1}$ to $\sim 1453 \mathrm{~cm}^{-1}$. In the unlabeled species the methoxy-methyl bending mode is found at $1450 \mathrm{~cm}^{-1}$. So upon ${ }^{18} \mathrm{O}$ labeling the $\mathrm{C}$...O modes and methyl bending modes will be similar in frequency and are therefore expected to strongly mix. 
TABLE 2: Calculated vibrational frequencies (in $\mathrm{cm}^{-1}$ ), intensities (in $\mathrm{km} / \mathrm{mol}$ ), Raman activities (in $\AA^{4} / \mathrm{amu}$ ), and potential energy distributions (\%) of normal modes that contain contributions from $\mathrm{C} \cdots \mathrm{O}$ and/or C...C groups (R3, R9, R4, and R10) of unlabeled, ${ }^{13} \mathrm{C}-$, and ${ }^{18} \mathrm{O}$-labeled $\mathrm{UQ}_{1 \mathrm{~F}}{ }^{-}$in (a) the gas phase and (b) $\mathrm{CCl}_{4}$. Only contributions to the $\mathrm{PED}$ above $5 \%$ are considered. Frequencies are scaled by a factor 0.9808 . For ${ }^{18} \mathrm{O}$ isotope labeling only the carbonyl oxygen atoms are labeled. $\mathrm{R}_{i}=i$ th bond stretching; $\delta \mathrm{C}_{i}=\mathrm{X}-\mathrm{C}_{i}-\mathrm{X}$ bending for $-\mathrm{CH}_{3}$, $-\mathrm{CH}_{2}-$ and $-\mathrm{CH}=$ groups; $\mathrm{X}=$ atom bonded to $\mathrm{C}_{i}$; $\mathrm{RD} 1=6^{-1 / 2}(\alpha 1-\alpha 2+\alpha 3-\alpha 4+\alpha 5-\alpha 6) ; \mathrm{RD} 2=12^{-1 / 2}(2 \alpha 1-\alpha 2-\alpha 3+2 \alpha 4-\alpha 5-\alpha 6)=$ ring deformation; $\alpha_{i}=\mathrm{C}_{i-1}-\mathrm{C}_{i}-\mathrm{C}_{i+1}$ angle bending of ring atoms.

(a) Gas phase

\begin{tabular}{|c|c|c|c|}
\hline$v$ & IR & Raman & Potential energy distribution \\
\hline \multicolumn{4}{|r|}{ Unlabeled } \\
\hline 1448 & 94 & 5 & $\mathrm{R} 1(6)-\mathrm{R} 6(5)+\delta \mathrm{C} 8(26)+\delta \mathrm{C} 9(25)$ \\
\hline 1461 & 16 & 10 & $\mathrm{R} 3(9)-\mathrm{R} 10(5)+\delta \mathrm{C} 10(26)+\delta \mathrm{C} 7(31)+\delta \mathrm{C} 9(8)$ \\
\hline 1495 & 33 & 247 & $\mathrm{R} 9(34)+\mathrm{R} 3(22)-\mathrm{R} 10(10)+\delta \mathrm{C} 7(8)$ \\
\hline 1500 & 287 & 3 & $\mathrm{R} 3(29)-\mathrm{R} 9(27)+\mathrm{RD}(9)+\delta \mathrm{C} 14(9)$ \\
\hline 1524 & 30 & 21 & $\mathrm{R} 4(33)-\mathrm{R} 10(16)-\mathrm{R} 5(6)-\mathrm{R} 7(6)+\delta \mathrm{C} 7(6)$ \\
\hline 1608 & 9 & 451 & $\mathrm{R} 4(26)+\mathrm{R} 10(23)+\mathrm{RD}(12)$ \\
\hline \multicolumn{4}{|r|}{${ }^{13} \mathrm{C}$} \\
\hline 1419 & 7 & 23 & $\delta \mathrm{C} 9(29)+\delta \mathrm{C} 8(22)+\mathrm{R} 4(12)-\mathrm{R} 10(11)+\mathrm{R} 3(6)$ \\
\hline 1430 & 218 & 6 & $\delta \mathrm{C} 8(35)-\mathrm{R} 3(20)+\mathrm{R} 9(8)+\delta \mathrm{C} 9(7)$ \\
\hline 1443 & 6 & 47 & $\delta \mathrm{C} 9(38)-\mathrm{R} 3(14)+\mathrm{R} 10(14)+\delta \mathrm{C} 7(7)-\mathrm{R} 9(6)$ \\
\hline 1458 & 13 & 61 & $\mathrm{R} 3(14)-\mathrm{R} 4(12)+\delta \mathrm{C} 9(10)+\delta \mathrm{C} 8(9)+\mathrm{R} 9(8)+\delta \mathrm{C} 7(6)+\mathrm{R} 10(6)$ \\
\hline 1459 & 195 & 25 & $\mathrm{R} 9(34)+\delta \mathrm{C} 8(22)+\delta \mathrm{C} 9(6)-\mathrm{RD} 1(6)-\mathrm{R} 10(5)$ \\
\hline 1474 & 8 & 130 & $\delta \mathrm{C} 8(32)+\delta \mathrm{C} 7(14)-\mathrm{R} 9(11)+\delta \mathrm{C} 9(20)-\mathrm{R} 3(6)$ \\
\hline 1481 & 23 & 23 & $\delta \mathrm{C} 14(37)+\delta \mathrm{C} 10(20)+\delta \mathrm{C} 13(13)+\mathrm{R} 3(7)$ \\
\hline 1519 & 34 & 18 & $\delta \mathrm{C} 7(33)-\mathrm{R} 4(15)+\delta \mathrm{C} 14(12)+\delta \mathrm{C} 13(5)$ \\
\hline 1550 & 7 & 384 & $\mathrm{R} 4(23)+\mathrm{R} 10(22)+\mathrm{RD} 2(11)$ \\
\hline \multicolumn{4}{|r|}{$x_{1}$} \\
\hline 1445 & 160 & 11 & $\delta \mathrm{C} 8(22)-\mathrm{R} 3(14)+\delta \mathrm{C} 9(12)+\mathrm{R} 1(8)-\mathrm{R} 6(6)$ \\
\hline 1455 & 11 & 53 & $\mathrm{R} 3(22)+\delta \mathrm{C} 9(21)+\delta \mathrm{C} 10(12)+\delta \mathrm{C} 7(8)-\mathrm{R} 10(6)+\mathrm{R} 9(5)$ \\
\hline 1466 & 10 & 33 & $\delta \mathrm{C} 14(24)+\delta \mathrm{C} 7(18)+\delta \mathrm{C} 13(16)+\delta \mathrm{C} 10(7)-\mathrm{R} 9(6)$ \\
\hline 1466 & 27 & 17 & $\delta \mathrm{C} 13(20)+\delta \mathrm{C} 7(19)+\delta \mathrm{C} 14(19)+\mathrm{R} 9(9)$ \\
\hline 1479 & 108 & 115 & $\mathrm{R} 9(37)+\delta \mathrm{C} 8(28)$ \\
\hline 1482 & 62 & 46 & $\delta \mathrm{C} 7(41)-\mathrm{R} 3(12)+\delta \mathrm{C} 14(5)$ \\
\hline 1486 & 46 & 33 & $\delta \mathrm{C} 13(57)+\delta \mathrm{C} 14(10)-\mathrm{R} 3(8)$ \\
\hline 1488 & 28 & 7 & $\delta \mathrm{C} 10(28)+\delta \mathrm{C} 13(23)+\delta \mathrm{C} 14(17)-\mathrm{R} 3(10)$ \\
\hline 1522 & 21 & 12 & $\mathrm{R} 4(31)-\mathrm{R} 10(20)+\delta \mathrm{C} 7(8)-\mathrm{R} 5(6)-\mathrm{R} 7(5)$ \\
\hline 1607 & 10 & 432 & $\mathrm{R} 4(27)+\mathrm{R} 10(24)+\mathrm{RD} 2(11)$ \\
\hline
\end{tabular}

(b) $\mathrm{CCl}_{4}$

\begin{tabular}{|c|c|c|c|}
\hline$v$ & IR & Raman & Potential energy distribution \\
\hline \multicolumn{4}{|c|}{ Unlabeled } \\
\hline 1450 & 134 & 6 & $\mathrm{R} 3(5)-\mathrm{R} 1(5)+\mathrm{R} 6(5)+\delta \mathrm{C} 8(29)+\delta \mathrm{C} 9(23)$ \\
\hline 1460 & 17 & 11 & $\mathrm{R} 3(9)+\delta \mathrm{C} 10(28)+\delta \mathrm{C} 7(27)+\delta \mathrm{C} 9(9)$ \\
\hline 1491 & 184 & 328 & $\mathrm{R} 9(56)-\mathrm{R} 10(8)$ \\
\hline 1495 & 238 & 163 & $\mathrm{R} 3(46)+\delta \mathrm{C} 13(14)+\mathrm{RD} 1(6)+\delta \mathrm{C} 7(5)+\delta \mathrm{C} 9(5)$ \\
\hline 1523 & 36 & 27 & $\mathrm{R} 4(32)-\mathrm{R} 10(17)-\mathrm{R} 5(6)-\mathrm{R} 7(6)+\delta \mathrm{C} 7(6)$ \\
\hline 1607 & 11 & 869 & $\mathrm{R} 4(27)+\mathrm{R} 10(23)+\mathrm{RD} 2(12)$ \\
\hline \multicolumn{4}{|c|}{${ }^{13} \mathrm{C}$} \\
\hline 1385 & 51 & 33 & $\delta \mathrm{C} 7(79)+\mathrm{R} 11(7)+\mathrm{R} 9(5)$ \\
\hline 1421 & 21 & 42 & $\delta \mathrm{C} 9(28)+\delta \mathrm{C} 8(18)-\mathrm{R} 10(13)+\mathrm{R} 4(11)+\mathrm{R} 3(9)$ \\
\hline 1431 & 365 & 7 & $\delta \mathrm{C} 8(32)-\mathrm{R} 3(24)+\mathrm{R} 9(11)$ \\
\hline 1443 & 15 & 91 & $\delta \mathrm{C} 9(39)+\mathrm{R} 10(14)-\mathrm{R} 9(12)-\mathrm{R} 3(11)+\delta \mathrm{C} 7(6)$ \\
\hline
\end{tabular}


(b) Continued.

\begin{tabular}{lccc}
\hline$v$ & IR & Raman & Potential energy distribution \\
\hline 1454 & 243 & 48 & $\mathrm{R} 9(32)+\delta \mathrm{C} 8(27)+\delta \mathrm{C} 9(12)-\mathrm{RD} 1(6)$ \\
1458 & 17 & 156 & $\mathrm{R} 3(15)-\mathrm{R} 4(11)+\delta \mathrm{C} 9(8)+\delta \mathrm{C} 8(8)+\mathrm{R} 9(7)+\mathrm{R} 10(6)+\delta \mathrm{C} 7(12)$ \\
1474 & 7 & 190 & $\delta \mathrm{C} 9(38)+\delta \mathrm{C} 8(23)+\delta \mathrm{C} 7(11)-\mathrm{R} 3(6)-\mathrm{R} 9(6)$ \\
1479 & 27 & 34 & $\delta \mathrm{C} 13(39)+\delta \mathrm{C} 10(19)+\delta \mathrm{C} 14(14)+\mathrm{R} 3(6)$ \\
1487 & 39 & 16 & $\delta \mathrm{C} 7(28)+\delta \mathrm{C} 13(24)-\mathrm{R} 4(13)+\delta \mathrm{C} 14(5)$ \\
1549 & 9 & 752 & $\mathrm{R} 4(24)+\mathrm{R} 10(22)+\mathrm{RD} 2(11)$ \\
\hline & & & $\delta \mathrm{C} 8(22)-\mathrm{R} 3(20)+\mathrm{R} 1(8)+\delta \mathrm{C} 9(6)-\mathrm{R} 6(6)$ \\
\hline 1446 & 259 & 19 & $\mathrm{R} 9(27)+\delta \mathrm{C} 7(18)+\delta \mathrm{C} 8(19)$ \\
1455 & 9 & 101 & $\delta \mathrm{C} 8(49)-\mathrm{R} 9(23)$ \\
1465 & 97 & 131 & $\delta \mathrm{C} 7(41)-\mathrm{R} 3(14)+\delta \mathrm{C} 9(10)$ \\
1476 & 112 & 112 & $\delta \mathrm{C} 14(52)+\delta \mathrm{C} 13(18)-\mathrm{R} 3(7)$ \\
1481 & 55 & 134 & $\mathrm{R} 4(30)-\mathrm{R} 10(21)+\delta \mathrm{C} 7(8)-\mathrm{R} 5(6)-\mathrm{R} 7(6)$ \\
1483 & 52 & 49 & $\mathrm{R} 4(28)+\mathrm{R} 10(24)+\mathrm{RD} 2(11)$ \\
1521 & 26 & 9 &
\end{tabular}

TABLE 3: Calculated and experimental frequencies of selected normal modes of UQ ${ }^{-}$. Isotope-induced frequency shifts are shown in parenthesis. Experimental Raman spectra have been obtained for $\mathrm{UQ}^{-}$in the $\mathrm{Q}_{\mathrm{A}}$ and $\mathrm{Q}_{\mathrm{B}}$ binding sites, and for $\mathrm{UQ}^{-}$in $\mathrm{DCM}^{\mathrm{C}}$ Calculated data are taken from Table 2(b).

\begin{tabular}{|c|c|c|c|c|c|c|c|c|}
\hline \multirow{2}{*}{ Mode } & \multicolumn{3}{|c|}{ Unlabeled } & \multicolumn{3}{|c|}{${ }^{13} \mathrm{C}$} & \multicolumn{2}{|c|}{${ }^{18} \mathrm{O}$} \\
\hline & Calc & $\operatorname{Raman}^{\mathrm{a}}$ & FTIR $^{b}$ & Calc & Ramana & FTIR $^{\mathrm{b}}$ & Calc & FTIR $^{\mathrm{b}}$ \\
\hline $\mathrm{C} \underline{\cdots} \mathrm{C}(\mathrm{s})$ & 1607 & $\begin{array}{c}1605 \mathrm{Q}_{\mathrm{A}} \\
1613 \mathrm{Q}_{\mathrm{B}} \\
1607(\mathrm{DCM})\end{array}$ & - & $1550(57)$ & $\begin{array}{c}1556(49) \mathrm{Q}_{\mathrm{A}} \\
1555(58) \mathrm{Q}_{\mathrm{B}}\end{array}$ & - & $1606(1)$ & \\
\hline $\mathrm{C} \ldots \mathrm{C}$ (as) & 1523 & $\begin{array}{c}1523 \mathrm{Q}_{\mathrm{A}} \\
1532 \mathrm{Q}_{\mathrm{B}} \\
1521(\mathrm{DCM})\end{array}$ & - & $\begin{array}{l}1458(65) \\
1487(36)\end{array}$ & $\begin{array}{l}1456(58) \\
1462(70)\end{array}$ & - & $1521(2)$ & \\
\hline $\mathrm{C} \cdots \mathrm{O}$ & $\begin{array}{l}1491 \\
1495\end{array}$ & $\begin{array}{c}1486 \mathrm{Q}_{\mathrm{A}} \\
1489 \mathrm{Q}_{\mathrm{B}} \\
1489(\mathrm{DCM})\end{array}$ & 1483 & $\begin{array}{l}1454(37) \\
1458(37)\end{array}$ & $\begin{array}{l}1456(30) \\
1462(27)\end{array}$ & $1442(41)$ & $\begin{array}{l}1476(15) \\
1465(26) \\
1481(14) \\
1483(12)\end{array}$ & $1468(15)$ \\
\hline
\end{tabular}

Data from resonance Raman experiments [10]. ${ }^{\mathrm{b}}$ Data from FTIR experiments [8]. For ${ }^{18} \mathrm{O}$ isotope labeling only the carbonyl oxygen atoms are labeled.

Table 2(b) shows that upon ${ }^{18} \mathrm{O}$ labeling the $\mathrm{C}$... O stretching vibrations do mix extensively with methyl bending vibrations, and that the $\mathrm{C}$... O modes are distributed amongst at least five different mixed modes. From the IR spectra in Figure 4(b), one could argue that the $1493 \mathrm{~cm}^{-1}$ band downshifts from $18 \mathrm{~cm}^{-1}$ to $1475 \mathrm{~cm}^{-1}$ upon ${ }^{18} \mathrm{O}$ labeling. Such an ${ }^{18} \mathrm{O}$ isotope-induced frequency shift for semiquinones is in line with experimental observations $[8,23]$ (see below).

\section{Discussion}

The calculated changes in frequency, intensity, and mode composition upon isotope labeling of ubisemiquinone are considerably more complex than those found for the neutral species [21]. In spite of this, however, the calculated data allow a clear and detailed interpretation of bands in experimental Raman and FTIR spectra of ubisemiquinone. The calculated IR and Raman spectra presented in Figure 4(b) correspond very well to experimental spectra [8-10].
4.1. Modeling Isotope-Induced Bandshifts Observed in Resonance Raman Spectra. Resonance Raman spectra of unlabeled and ${ }^{13} \mathrm{C}$-labeled $\mathrm{UQ}_{10}{ }^{-}$in the $\mathrm{Q}_{\mathrm{A}}$ and $\mathrm{Q}_{\mathrm{B}}$ binding sites in purple bacterial reaction centers have been obtained [10]. For comparison, resonance Raman spectra of unlabeled $\mathrm{UQ}_{10}{ }^{-}$in solution were also obtained [10]. For both in vivo and in vitro cases an intense Raman band was observed near $1608 \mathrm{~cm}^{-1}$, with weaker bands observed near 1523 and $1488 \mathrm{~cm}^{-1}$. We note that the calculated Raman spectrum for unlabeled $\mathrm{UQ}_{1}{ }^{-}$(Figure 4(b)) looks very similar to the experimental spectrum.

The $\sim 1608 \mathrm{~cm}^{-1}$ band was assigned to a C...C mode, weakly coupled to a $\mathrm{C} \cdots \mathrm{O}$ mode, because it downshifted to $49-58 \mathrm{~cm}^{-1}$ upon ${ }^{13} \mathrm{C}$ labeling [10] (Table 3). The $1488 \mathrm{~cm}^{-1}$ band was assigned to a $\mathrm{C} \ldots \mathrm{O}$ mode because it downshifted to $\sim 28 \mathrm{~cm}^{-1}$ upon ${ }^{13} \mathrm{C}$ labeling [10] (Table 3). The $\sim 1523 \mathrm{~cm}^{-1}$ band apparently disappears upon ${ }^{13} \mathrm{C}$ labeling. Although not suggested in the original manuscript, it is possible that the $1523 \mathrm{~cm}^{-1}$ band (of $\mathrm{UQ}_{10}{ }^{-}$in the $\mathrm{Q}_{\mathrm{A}}$ 

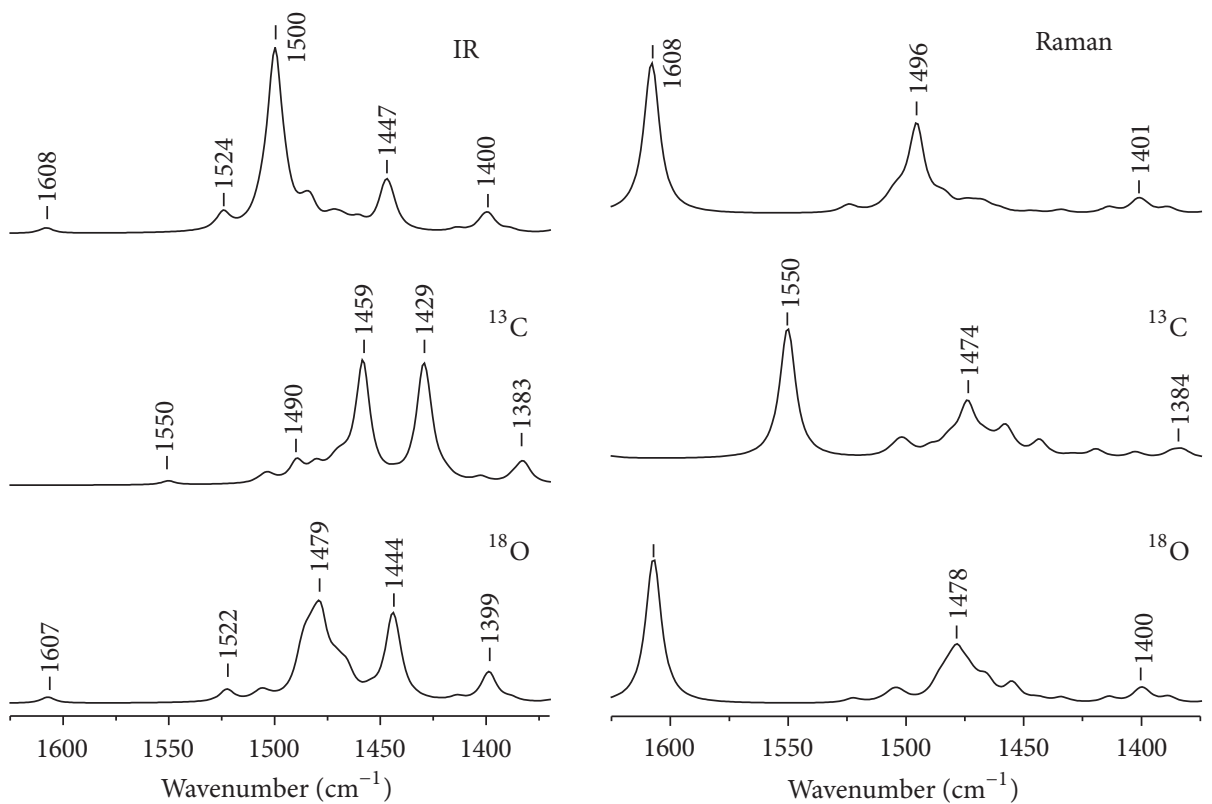

(a)
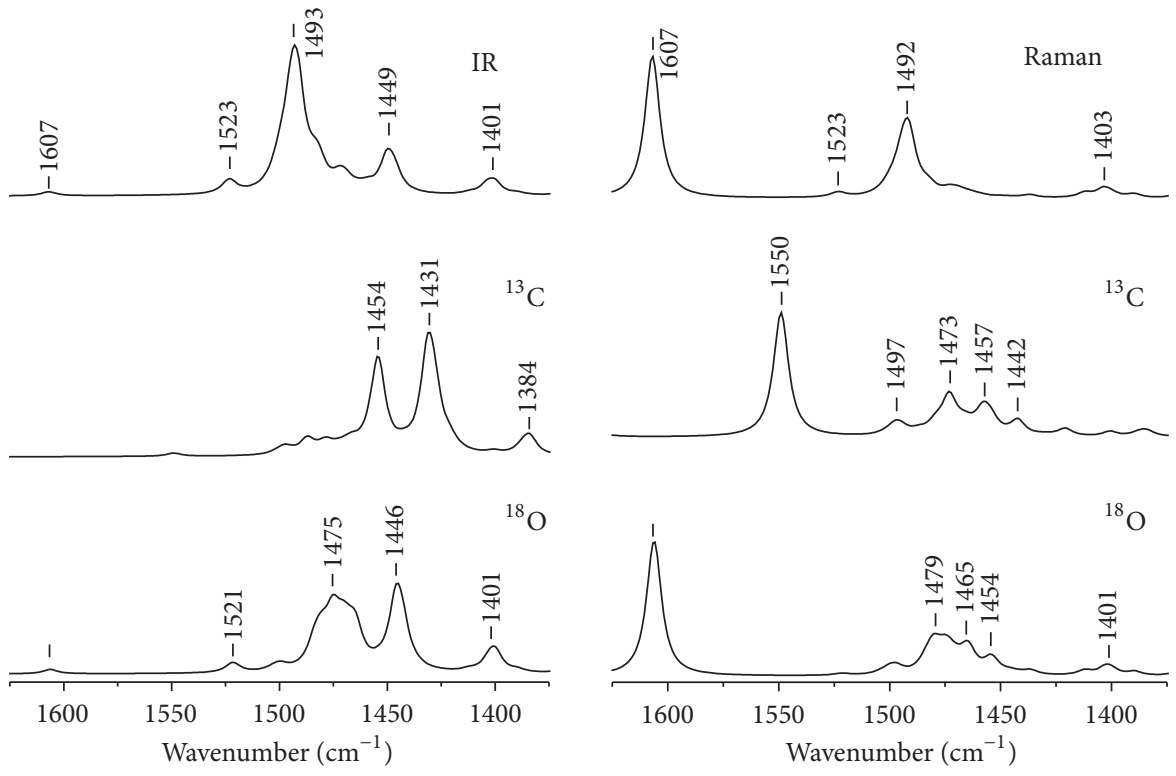

(b)

FIGURE 4: Calculated Boltzmann weighted composite IR (left) and Raman (right) spectra for unlabeled (top), ${ }^{13} \mathrm{C}\left(\right.$ middle), and ${ }^{18} \mathrm{O}($ bottom) labeled $\mathrm{UQ}_{1}{ }^{-}$in (a) the gas phase and (b) $\mathrm{CCl}_{4}$. For ${ }^{18} \mathrm{O}$ isotope labeling only the carbonyl oxygen atoms are labeled.

binding site) downshifts from $\sim 67 \mathrm{~cm}^{-1}$ to $1456 \mathrm{~cm}^{-1}$ upon ${ }^{13} \mathrm{C}$ labeling, and is masked by the ${ }^{13} \mathrm{C} \cdot \mathrm{O} \mathrm{O}$ band at $1456 \mathrm{~cm}^{-1}$ (Table 3).

In our calculations the $\mathrm{C}_{2} \cdots \mathrm{C}_{3}$ and $\mathrm{C}_{5} \cdots \mathrm{C}_{6}$ stretching vibrations couple to give $\mathrm{C} \cdots \mathrm{C}$ in-phase and out-of-phase vibrations. For $\mathrm{UQ}_{1}{ }^{-}$in $\mathrm{CCl}_{4}$ the $\mathrm{C} . . \mathrm{C}$ in-phase vibration is at $1607 \mathrm{~cm}^{-1}$ (Figure 4(b)). This is $84 \mathrm{~cm}^{-1}$ higher in frequency than the out-of-phase vibration (at $1523 \mathrm{~cm}^{-1}$ ).
Unlike the out-of-phase vibration, the in-phase vibration is not coupled with methyl bending and carbonyl stretching modes (Table 2(b)). The C $\cdots \mathrm{C}$ in-phase vibration has negligible IR intensity but huge Raman activity. It is basically unaffected by ${ }^{18} \mathrm{O}$ labeling, but downshifts to $57 \mathrm{~cm}^{-1}$ upon ${ }^{13} \mathrm{C}$ labeling. The intensely Raman active band calculated at $1607 \mathrm{~cm}^{-1}$ for $\mathrm{UQ}_{1}{ }^{-}$clearly corresponds to the band observed at $\sim 1608 \mathrm{~cm}^{-1}$ experimentally [10]. 
The out-of-phase C...C vibrational mode at $1523 \mathrm{~cm}^{-1}$ mixes with other modes upon ${ }^{13} \mathrm{C}$ labeling and is not easily identifiable. A strongly Raman active mode of ${ }^{13} \mathrm{C}$-labeled $\mathrm{UQ}^{-}$is calculated at $1458 \mathrm{~cm}^{-1}$ (Table 2(b)). The out-of-phase C … V vibration contributes $17 \%$ to the PED of this mode [R10(6\%)-R4(11\%)]. The in-phase-coupled vibration of both $\mathrm{C} \cdot \cdots \mathrm{O}$ groups $[\mathrm{R} 3(15 \%)+\mathrm{R} 9(7 \%)]$ also contributes to this mode.

Clearly, the calculated out-of-phase C...C vibrational mode at $1523 \mathrm{~cm}^{-1}$ can be associated with the band observed at $\sim 1521 \mathrm{~cm}^{-1}$ in resonance Raman spectra of $\mathrm{UQ}^{-}$in solution [10]. We suggest that the mode calculated at $1523 \mathrm{~cm}^{-1}$ forms part of a new mode that appears at $1458 \mathrm{~cm}^{-1}$ upon ${ }^{13} \mathrm{C}$ labeling (Table 3). In phase ${ }^{13} \mathrm{C} \cdots \mathrm{O}$ vibrations also contribute to the $1458 \mathrm{~cm}^{-1}$ mode. Our calculated data therefore provides an explanation as to why the $\sim 1521 \mathrm{~cm}^{-1}$ resonance Raman band that is observed experimentally is not identified in spectra of ${ }^{13} \mathrm{C}$-labeled $\mathrm{UQ}^{-}$[10]. Upon ${ }^{13} \mathrm{C}$ labeling the $\mathrm{C} \cdots \mathrm{C}$ mode mixes with $\mathrm{C} \cdots \mathrm{O}$ modes (and methyl bending modes) to become a new mode that is not distinctly identifiable as a ${ }^{13} \mathrm{C} .{ }^{13} \mathrm{C}$ mode.

Bands at $1486 / 1489 \mathrm{~cm}^{-1}$ in resonance Raman spectra of $\mathrm{UQ}^{-}$in the $\mathrm{Q}_{A} / \mathrm{Q}_{B}$ binding site downshift $30 / 27 \mathrm{~cm}^{-1}$ upon ${ }^{13} \mathrm{C}$ labeling of $\mathrm{UQ}^{-}$(Table 3), respectively. They were therefore associated with $\mathrm{C} \cdot \cdots \mathrm{O}$ modes coupled to $\mathrm{C} \cdots \mathrm{C}$ modes. Computationally, we find two $\mathrm{C} \cdots \mathrm{O}$ modes at 1495 and $1491 \mathrm{~cm}^{-1}$. Both modes are Raman active with the $1491 \mathrm{~cm}^{-1}$ mode displaying the greater activity (Table 2(b)). These modes give rise to the $1492 \mathrm{~cm}^{-1}$ band in the calculated Raman spectrum (Figure 3(b)), which appears to downshift $19 / 35 \mathrm{~cm}^{-1}$ to $1473 / 1457 \mathrm{~cm}^{-1}$ upon ${ }^{13} \mathrm{C}$-labeling. The $1473 / 1457 \mathrm{~cm}^{-1}$ band in the calculated Raman spectrum for

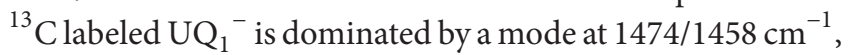
respectively. The $1474 \mathrm{~cm}^{-1}$ mode and to a lesser degree the $1458 \mathrm{~cm}^{-1}$ mode are due predominantly to methyl $\mathrm{CH}$ bending vibrations of both methoxy groups coupled to a $\mathrm{C}_{1} \ldots \mathrm{O}$ vibration. Notice that the coupling of the $\mathrm{C}_{1} \ldots \mathrm{O}$ vibration is to methoxy methyl $\mathrm{CH}$ bending vibrations, not $\mathrm{C} \cdot \mathrm{C} \mathrm{C}$ ring vibrations, as was originally proposed based on the experimental spectra.

4.2. Modeling Isotope-Induced Bandshifts Observed in FTIR Spectra. Electrochemically generated FTIR difference spectra of UQ in various solvents have been obtained [8]. For $\mathrm{UQ}_{10}{ }^{-}$in acetonitrile, THF, or dichloromethane an intense FTIR absorption band was observed at $1483-1488 \mathrm{~cm}^{-1}$. The observation of predominantly a single intense band in experimental FTIR spectra of unlabeled $\mathrm{UQ}_{10}{ }^{-}$and $\mathrm{UQ}_{1}{ }^{-}$in solution is in line with our calculated IR spectra, which are dominated by an intense band at $1478-1493 \mathrm{~cm}^{-1}$ for $\mathrm{UQ}_{1}{ }^{-}$ in a variety of solvents (Figures 3(b) and 3(c)).

In experimental FTIR difference spectra for $\mathrm{UQ}_{1}{ }^{-}$in dichloromethane, a band is observed at $1483 \mathrm{~cm}^{-1}$, which downshifts to $41 \mathrm{~cm}^{-1}$ upon ${ }^{13} \mathrm{C}$ labeling (Table 3) [8]. From Figure 3(b) it can be seen that upon ${ }^{13} \mathrm{C}$ labeling the $1493 \mathrm{~cm}^{-1}$ band downshifts from $39 \mathrm{~cm}^{-1}$ to $1454 \mathrm{~cm}^{-1}$. The calculated result therefore agrees very well with the experimental observation.

Experimentally, for $\mathrm{UQ}_{1}{ }^{-}$in dichloromethane, it is also observed that the $1483 \mathrm{~cm}^{-1}$ band downshifts from $15 \mathrm{~cm}^{-1}$ to $1468 \mathrm{~cm}^{-1}$ upon ${ }^{18} \mathrm{O}$ labeling. From the calculated IR spectra in Figure 4(b), the most obvious suggestion is that the $1493 \mathrm{~cm}^{-1}$ band (of unlabeled $\mathrm{UQ}_{1}^{-}$) downshifts from $18 \mathrm{~cm}^{-1}$ to $1475 \mathrm{~cm}^{-1}$ upon ${ }^{18} \mathrm{O}$ labeling. The calculated PEDs in Table 2(b) indicate a complicated situation: the 1495 and $1491 \mathrm{~cm}^{-1}$ modes of unlabeled $\mathrm{UQ}_{1}{ }^{-}$are due to the $\mathrm{C}$... O groups (R3 and R9, resp.). Upon ${ }^{18} \mathrm{O}$ labeling modes appear at 1476 [R9(23\%)] and $1465 \mathrm{~cm}^{-1}$ [R9(27\%)]. Thus, the $1491 \mathrm{~cm}^{-1}$ mode in the unlabeled species appears to split and downshift to 15 and $26 \mathrm{~cm}^{-1}$ upon ${ }^{18} \mathrm{O}$ labeling (Table $3)$. The former is in excellent agreement with experiment [8]. Upon ${ }^{18} \mathrm{O}$ labeling modes also appear at 1481 [R3(14\%)] and $1483 \mathrm{~cm}^{-1}$ [R3(7\%)]. Thus, the $1495 \mathrm{~cm}^{-1}$ mode in the unlabeled species also appears to split and downshift to 14 and $12 \mathrm{~cm}^{-1}$ upon ${ }^{18} \mathrm{O}$ labeling (Table 3). Again, these conclusions are in good agreement with experiment [8]. It is the plethora of mixed modes that appear upon ${ }^{18} \mathrm{O}$ labeling that give rise to the broad band with a peak near $1475 \mathrm{~cm}^{-1}$ in the calculated spectrum (Figure 3(b)). Unfortunately FTIR spectra for ${ }^{18} \mathrm{O}$-labeled $\mathrm{UQ}_{1}{ }^{-}$have never been presented. Only the observed shifts upon labeling were presented.

From electrochemically generated FTIR difference spectra of ${ }^{13} \mathrm{C}$-labeled $\mathrm{UQ}_{10}{ }^{-}$in various solvents [8] a band was observed at $1412 \mathrm{~cm}^{-1}$. It was suggested that this band was due to a ${ }^{13} \mathrm{C} .{ }^{13} \mathrm{C}$ vibration that was downshifted to $71 \mathrm{~cm}^{-1}$ from $1483 \mathrm{~cm}^{-1}$ in the unlabeled species. Neither the calculated data presented here nor the resonance Raman data presented previously support this hypothesis.

4.3. Experimental $Q_{A}{ }^{-} / Q_{A}$ and $Q_{B}{ }^{-} / Q_{B}$ FTIR DS. $Q_{A}{ }^{-} / Q_{A}$ and $\mathrm{Q}_{\mathrm{B}}{ }^{-} / \mathrm{Q}_{\mathrm{B}}$ FTIR $\mathrm{DS}$ have been obtained using PBRCs from $R$. sphaeroides [7, 24-27]. In $\mathrm{Q}_{\mathrm{A}}{ }^{-} / \mathrm{Q}_{\mathrm{A}}$ FTIR DS three intense IR bands are observed near 1485,1466 , and $1449 \mathrm{~cm}^{-1}$ $[24,25]$. On the basis of ${ }^{18} \mathrm{O},{ }^{13} \mathrm{C},{ }^{13} \mathrm{C}_{1}$, and ${ }^{13} \mathrm{C}_{4}$ labeling the $1486 / 1466 \mathrm{~cm}^{-1}$ bands were assigned to $\mathrm{C} \cdots \mathrm{O} / \mathrm{C} \cdots \mathrm{C}$ vibrations, respectively [24]. The modes were suggested to be considerably mixed. The origin of the $1449 \mathrm{~cm}^{-1}$ band was not considered.

Another group, which undertook identical labeling experiments [25], assigned the $1485 \mathrm{~cm}^{-1}$ band to a $\mathrm{C}_{1} \cdots \mathrm{O}$ vibration, the $1466 \mathrm{~cm}^{-1}$ band to $\mathrm{C}_{4}=\mathrm{O}$ vibration, and the $1449 \mathrm{~cm}^{-1}$ band to a C...C vibration. All modes were suggested to be strongly mixed.

Resonance Raman spectra for $\mathrm{UQ}^{-}$in the $\mathrm{Q}_{\mathrm{A}}$ binding site display a weak band at $1486 \mathrm{~cm}^{-1}$, but no bands were apparent at 1466 and $1449 \mathrm{~cm}^{-1}$. Of course it may simply be the case that the 1466 and $1449 \mathrm{~cm}^{-1}$ normal modes are Raman inactive.

Our calculated spectra for $\mathrm{UQ}_{1}{ }^{-}$in solution poorly model observed FTIR bands of $\mathrm{UQ}^{-}$in the $\mathrm{Q}_{\mathrm{A}}$ binding site. For $\mathrm{UQ}^{-}$ 
in the $\mathrm{Q}_{\mathrm{A}}$ binding site, the $\mathrm{C} \cdots \mathrm{O}$ modes appear to be separated by $19 \mathrm{~cm}^{-1}$. For calculations in solvent the two $\mathrm{C} \cdots \mathrm{O}$ modes do appear to be distinct, although the separation of the modes is only $4 \mathrm{~cm}^{-1}$. In gas phase calculations the two $\mathrm{C} \ldots \mathrm{O}$ modes are coupled. The separation of $\mathrm{C} \ldots \mathrm{O}$ modes of $\overline{\mathrm{UQ}}^{-}$ in the $\mathrm{Q}_{\mathrm{A}}$ binding site is due to asymmetric interactions with the protein environment. Calculations of $\mathrm{UQ}^{-}$in solvent or in the gas phase cannot model these interactions. Calculations including effects of the protein environment are essential. Such calculations are underway in our lab.

In $\mathrm{Q}_{\mathrm{B}}{ }^{-} / \mathrm{Q}_{\mathrm{B}}$ FTIR DS a single IR band is observed near $1479 \mathrm{~cm}^{-1}$. It was suggested that this band was due to both $\mathrm{C} \cdots \mathrm{O}$ modes of $\mathrm{UQ}^{-}$in the $\mathrm{Q}_{\mathrm{B}}$ binding site [7, $26,27]$. It was also suggested that the $1479 \mathrm{~cm}^{-1}$ band downshifts $33 / 52 \mathrm{~cm}^{-1}$ upon ${ }^{18} \mathrm{O} /{ }^{13} \mathrm{C}$ labeling, respectively $[7,26,27]$. Such shifts are difficult to rationalize in view of the shifts calculated $\left(15 / 37 \mathrm{~cm}^{-1}\right)$ and observed experimentally $\left(15 / 27-41 \mathrm{~cm}^{-1}\right)$ for UQ in solution (Table 3). Additionally, there appears to be some inequivalence in the $\mathrm{C}$... $\mathrm{C}$ modes of $U Q$ in the $Q_{B}$ binding site when perturbed specifically at the $\mathrm{C}_{1}$ or $\mathrm{C}_{4}$ position [7,26,27]. It was suggested that this inequivalence is a result of specific protein interactions $[7,26,27]$. Again, calculations including effects of the protein environment appear to be necessary (essential) in order to accurately simulate the vibrational spectra of $U Q$ in the $Q_{B}$ binding site.

4.4. Previous Calculations of Ubisemiquinones. DFT-based vibrational frequency calculations (using the BP86 functional) have been undertaken for 2,3-dimethoxy-1,4-benzoquinone and 2,3-dimethoxy-5,6-dimethyl-1,4-benzoquinone in the gas phase [12]. Comparison of calculated data for the two models showed that substituents at $\mathrm{C}_{5}$ and $\mathrm{C}_{6}$ are required in order to better model the properties of ubiquinones and ubisemiquinones. In the above study isotope shifts were calculated. However how the $\mathrm{C} \ldots \mathrm{O}$ and $\mathrm{C} \cdot \cdots \mathrm{C}$ modes couple with each other and with $\mathrm{CH}$ methoxy methyl bending vibrations was not considered. As we have shown above, the extent of mode mixing can be considerably altered upon labeling, making it difficult to identify how the different bands shift upon labeling. As we show here, the detailed PEDs are a crucial tool in the analysis of how calculated bands shift upon isotope labeling.

One problem with previous DFT calculations (in the gas phase) [12] is that for 2,3-dimethoxy-1,4-benzoquinone the $\mathrm{C}$... O modes were found at a higher frequency than the $\mathrm{C}$... $\mathrm{C}$ modes. For 2,3-dimethoxy-5,6-dimethyl-1,4-benzoquinone (in the gas phase) the $\mathrm{C}$-.. O modes were found at slightly lower frequency than the $\overline{\mathrm{C}} \cdots \mathrm{C}$ modes $\left(3-4 \mathrm{~cm}^{-1}\right)$. However, from Raman experiments the out-of-phase C... $\mathrm{C}$ mode is found to be $\sim 32 \mathrm{~cm}^{-1}$ higher in frequency than the $\mathrm{C} \ldots \mathrm{O}$ mode [10] (Table 3).

Furthermore, the antisymmetrically coupled $\mathrm{C}$... O mode (for 2,3-dimethoxy-5,6-dimethyl-1,4-benzoquinone) was calculated to be more than a factor of 26 times more intense than the C...C mode [12]. This calculated result is not in line with experimental IR spectra [8].
Clearly, previous DFT calculations [12] poorly model the experimental Raman and IR spectra. In contrast, in our calculations for $\mathrm{UQ}_{1}{ }^{-}$in $\mathrm{CCl}_{4}$, the out-of-phase $\mathrm{C} \cdots \mathrm{C}$ modes are $28-32 \mathrm{~cm}^{-1}$ higher in frequency than either of the $\mathrm{C} \ldots \mathrm{O}$ mode (Table 2(b)). In gas phase calculations the out-of-phase $\mathrm{C} \ldots \mathrm{C}$ mode is still $24 \mathrm{~cm}^{-1}$ higher in frequency than the antisymmetrically coupled C...O mode (Table $2(\mathrm{a})$ ). In addition, in gas phase calculations and in solvent, the intensity of antisymmetrically coupled $\mathrm{C} \cdots \mathrm{O}$ mode is $\sim 7.5$ times more intense than the out-of-phase $\overline{\mathrm{C}} \cdot \ldots \mathrm{C}$ mode. These results are in excellent agreement with experimental IR and Raman spectra. The limitations in previous calculations are most likely related to the choice of functional and basis set, and the inadequacy of a UQ structural model that lacks an isoprene unit.

\section{Conclusions}

We calculate that four $\mathrm{UQ}_{1}{ }^{-}$conformers are likely present in solution at room temperature. Calculated IR spectra for all four $\mathrm{UQ}_{1}{ }^{-}$conformers are similar. Calculated IR spectra of unlabeled and isotope-labeled $\mathrm{UQ}_{1}{ }^{-}$in the gas phase and in solution show a similar band pattern, although in some cases there are differences in the composition of the modes that contribute to the bands in the spectra.

Calculations show that upon isotope labeling the out-ofphase $\mathrm{C} \cdots \mathrm{C}$ ring modes and $\mathrm{C} \cdot \mathrm{\cdots} \mathrm{O}$ modes of $\mathrm{UQ}_{1}{ }^{-}$strongly couple with methyl $\mathrm{C}-\mathrm{H}$ bending vibrations of the methoxy groups. This leads to complicated splitting of modes and unusual downshifts upon isotope labeling. Nonetheless by consideration of PEDs of the calculated normal modes, sense can be made of the isotope-induced shifts and intensity changes, and it is shown that the calculated data provide a rational and detailed interpretation of experimentally observed isotope-induced band shifts in experimental FTIR and Raman spectra of $\mathrm{UQ}_{1}{ }^{-}$in solution.

\section{Abbreviations}

DFT: Density functional theory

DS: Difference spectra

FTIR: Fourier transform infrared

IR: Infrared

IEF: Integral equation formalism

PBRCs: Purple bacterial reaction centers

PCM: Polarizable continuum model

PED: Potential energy distribution

UQ: Ubiquinone

$\mathrm{UQ}^{-}$: Ubisemiquinone.

\section{Acknowledgments}

H. P. Lamichhane acknowledge support from a fellowship from the Molecular Basis of Disease Program at Georgia State University. G. Hastings acknowledges the support from Qatar National Research Fund. 


\section{References}

[1] B. Trumpower, Function of Quinones in Energy Conserving Systems, Academic Press, 1982.

[2] B. Ke, "The bacterial photosynthetic reaction center: chemical composition and crystal structure," in Photosynthesis: Photobiochemistry and Photobiophysics, pp. 47-62, Kluwer Academic Publishers, Dordrecht, The Netherlands, 2001.

[3] B. Ke, "The, "Stable" primary electron acceptor $\left(\mathrm{Q}_{\mathrm{A}}\right)$ of photosynthetic bacteria," in Photosynthesis: Photobiochemistry and Photobiophysics, pp. 101-110, Kluwer Academic Publishers, Dordrecht, The Netherlands, 2001.

[4] B. Ke, "The secondary electron acceptor $\left(\mathrm{Q}_{\mathrm{B}}\right)$ of photosynthetic bacteria," in Photobiochemistry and Photobiophysics, pp. 111-128, Kluwer Academic Publishers, Dordrecht, The Netherlands, 2001.

[5] N. Srinivasan and J. H. Golbeck, "Protein-cofactor interactions in bioenergetic complexes: the role of the A1A and A1B phylloquinones in Photosystem I," Biochimica et Biophysica Acta, vol. 1787, no. 9, pp. 1057-1088, 2009.

[6] C. A. Wraight and M. R. Gunner, "The acceptor quinones of purple photosynthetic Bacteria-structure and spectroscopy," in The Purple Photosynthetic Bacteria, C. N. Hunter, F. Daldal, M. C. Thurnauer, and J. T. Beatty, Eds., pp. 379-405, Springer, 2009.

[7] J. Breton and E. Nabedryk, "Protein-quinone interactions in the bacterial photosynthetic reaction center: light-induced FTIR difference spectroscopy of the quinone vibrations," Biochimica et Biophysica Acta, vol. 1275, no. 1-2, pp. 84-90, 1996.

[8] M. Bauscher and W. Mäntele, "Electrochemical and infraredspectroscopic characterization of redox reactions of $\mathrm{p}$ quinones," Journal of Physical Chemistry, vol. 96, no. 26, pp. 11101-11108, 1992.

[9] M. Bauscher, E. Nabedryk, K. Bagley, J. Breton, and W. Mantele, "Investigation of models for photosynthetic electron acceptors. Infrared spectroelectrochemistry of ubiquinone and its anions," FEBS Letters, vol. 261, no. 1, pp. 191-195, 1990.

[10] X. Zhao, T. Ogura, M. Okamura, and T. Kitagawa, “Observation of the resonance raman spectra of the semiquinones QA-and QB-- in photosynthetic reaction centers from Rhodobacter sphaeroides R26," Journal of the American Chemical Society, vol. 119, pp. 5263-5264, 1997.

[11] G. Balakrishnan, P. Mohandas, and S. Umapathy, "Ab initio studies on structure and vibrational spectra of ubiquinone and its radical anion," Spectrochimica Acta A, vol. 53, no. 10, pp. 1553-1561, 1997.

[12] M. Nonella, "A density functional investigation of model molecules for ubisemiquinone radical anions," Journal of Physical Chemistry B, vol. 102, no. 21, pp. 4217-4225, 1998.

[13] M. J. Frisch, G. W. Trucks, H. B. Schlegel et al., 2004.

[14] K. M. Bandaranayake, V. Sivakumar, R. Wang, and G. Hastings, "Modeling the A1 binding site in photosystem. I. Density functional theory for the calculation of "anion-neutral" FTIR difference spectra of phylloquinone," Vibrational Spectroscopy, vol. 42, no. 1, pp. 78-87, 2006.

[15] E. Cancès, C. Le Bris, B. Mennucci, and J. Tomasi, "Integral equation methods for molecular scale calculations in the liquid phase," Mathematical Models and Methods in Applied Sciences, vol. 9, no. 1, pp. 35-44, 1999.
[16] E. Cancès, B. Mennucci, and J. Tomasi, "A new integral equation formalism for the polarizable continuum model: theoretical background and applications to Isotropic and anisotropic dielectrics," Journal of Chemical Physics, vol. 107, no. 8, pp. 3032-3041, 1997.

[17] J. Tomasi, B. Mennucci, and E. Cancès, "The IEF version of the PCM solvation method: an overview of a new method addressed to study molecular solutes at the QM ab initio level," Journal of Molecular Structure, vol. 464, no. 1-3, pp. 211-226, 1999.

[18] J. Tomasi, R. Cammi, B. Mennucci, C. Cappelli, and S. Corni, "Molecular properties in solution described with a continuum solvation model," Physical Chemistry Chemical Physics, vol. 4, no. 23, pp. 5697-5712, 2002.

[19] J. Tomasi, B. Mennucci, and R. Cammi, "Quantum mechanical continuum solvation models," Chemical Reviews, vol. 105, no. 8, pp. 2999-3093, 2005.

[20] J. M. L. Martin and C. Van Alsenoy, GAR2PED, University of Antwerp, 1995.

[21] H. Lamichhane, R. Wang, and G. Hastings, "Comparison of calculated and experimental FTIR spectra of specifically labeled ubiquinones," Vibrational Spectroscopy, vol. 55, no. 2, pp. 279-286, 2011.

[22] C. Cappelli, C. O. Silva, and J. Tomasi, "Solvent effects on vibrational modes: ab-initio calculations, scaling and solvent functions with applications to the carbonyl stretch of dialkyl ketones," Journal of Molecular Structure, vol. 544, pp. 191-203, 2001.

[23] G. Hastings, K. M. P. Bandaranayake, and E. Carrion, "Timeresolved FTIR difference spectroscopy in combination with specific isotope labeling for the study of A1, the secondary electron acceptor in photosystem 1," Biophysical Journal, vol. 94, no. 11, pp. 4383-4392, 2008.

[24] J. Breton, J. R. Burie, C. Berthomieu, G. Berger, and E. Nabedry, "The binding sites of quinones in photosynthetic bacterial reaction centers investigated by light-induced FTIR difference spectroscopy: assignment of the $\mathrm{Q}_{\mathrm{A}}$ vibrations in Rhodobacter sphaeroides using ${ }^{18} \mathrm{O}$ - $\mathrm{Or}{ }^{13} \mathrm{C}$-labeled ubiquinone and vitamin $\mathrm{K}_{1}$," Biochemistry, vol. 33, no. 16, pp. 4953-4965, 1994.

[25] R. Brudler, H. J. M. De Groot, W. B. S. Van Liemt et al., "Asymmetric binding of the 1- and 4- $\mathrm{C}=\mathrm{O}$ groups of $\mathrm{Q}_{\mathrm{A}}$ in Rhodobacter sphaeroides $\mathrm{R} 26$ reaction centres monitored by Fourier transform infra-red spectroscopy using site-specific isotopically labelled ubiquinone-10," EMBO Journal, vol. 13, no. 23, pp. 5523-5530, 1994.

[26] J. Breton, C. Boullais, G. Berger, C. Mioskowski, and E. Nabedryk, "Binding sites of quinones in photosynthetic bacterial reaction centers investigated by light-induced FTIR difference spectroscopy: symmetry of the carbonyl interactions and close equivalence of the QB vibrations in Rhodobacter sphaeroides and Rhodopseudomonas viridis probed by isotope labeling," Biochemistry, vol. 34, no. 36, pp. 11606-11616, 1995.

[27] R. Brudler, H. J. M. De Groot, W. B. S. Van Liemt et al., "FTIR spectroscopy shows weak symmetric hydrogen bonding of the $\mathrm{Q}_{\mathrm{B}}$ carbonyl groups in Rhodobacter sphaeroides $\mathrm{R} 26$ reaction centres," FEBS Letters, vol. 370, no. 1-2, pp. 88-92, 1995. 

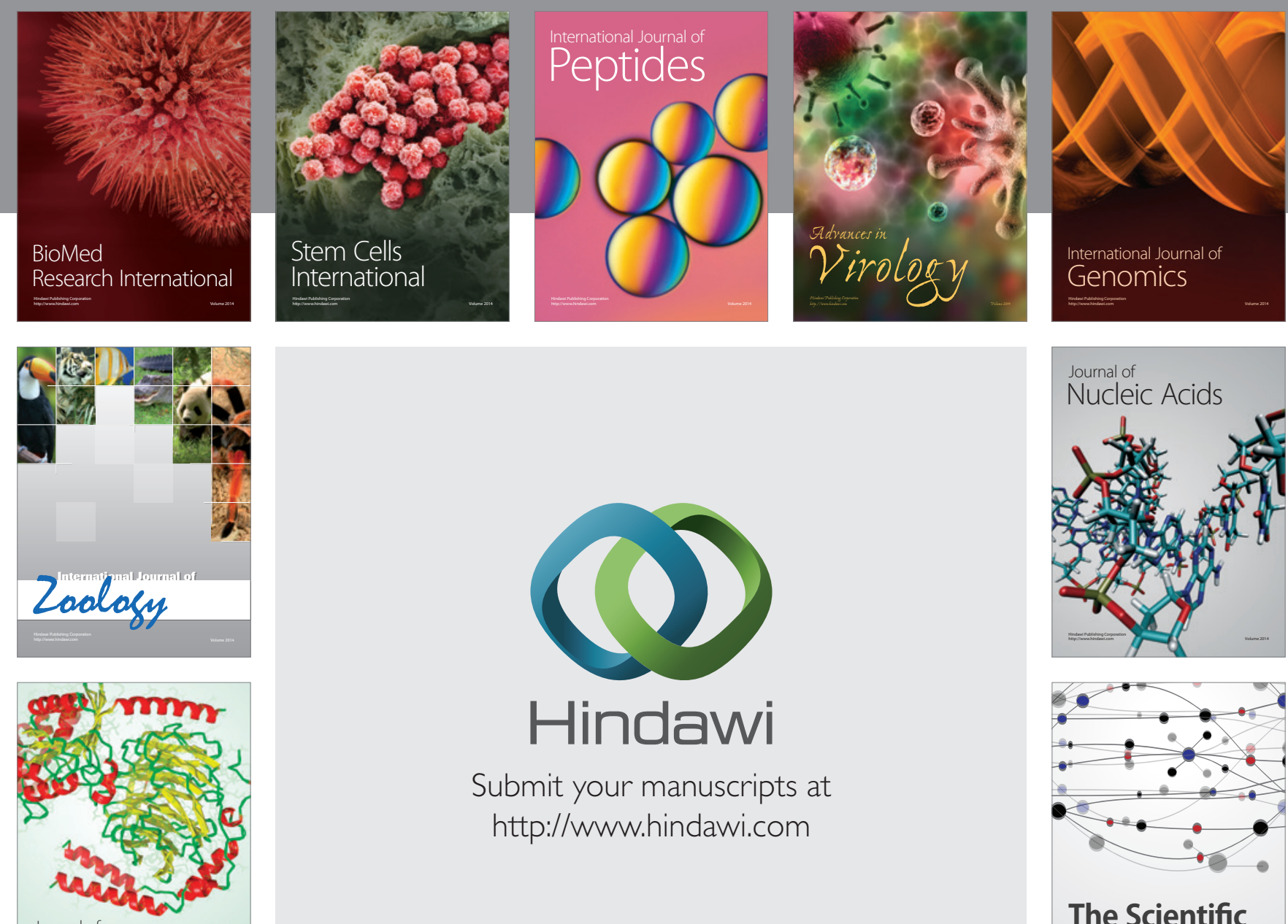

Submit your manuscripts at

http://www.hindawi.com

Journal of
Signal Transduction
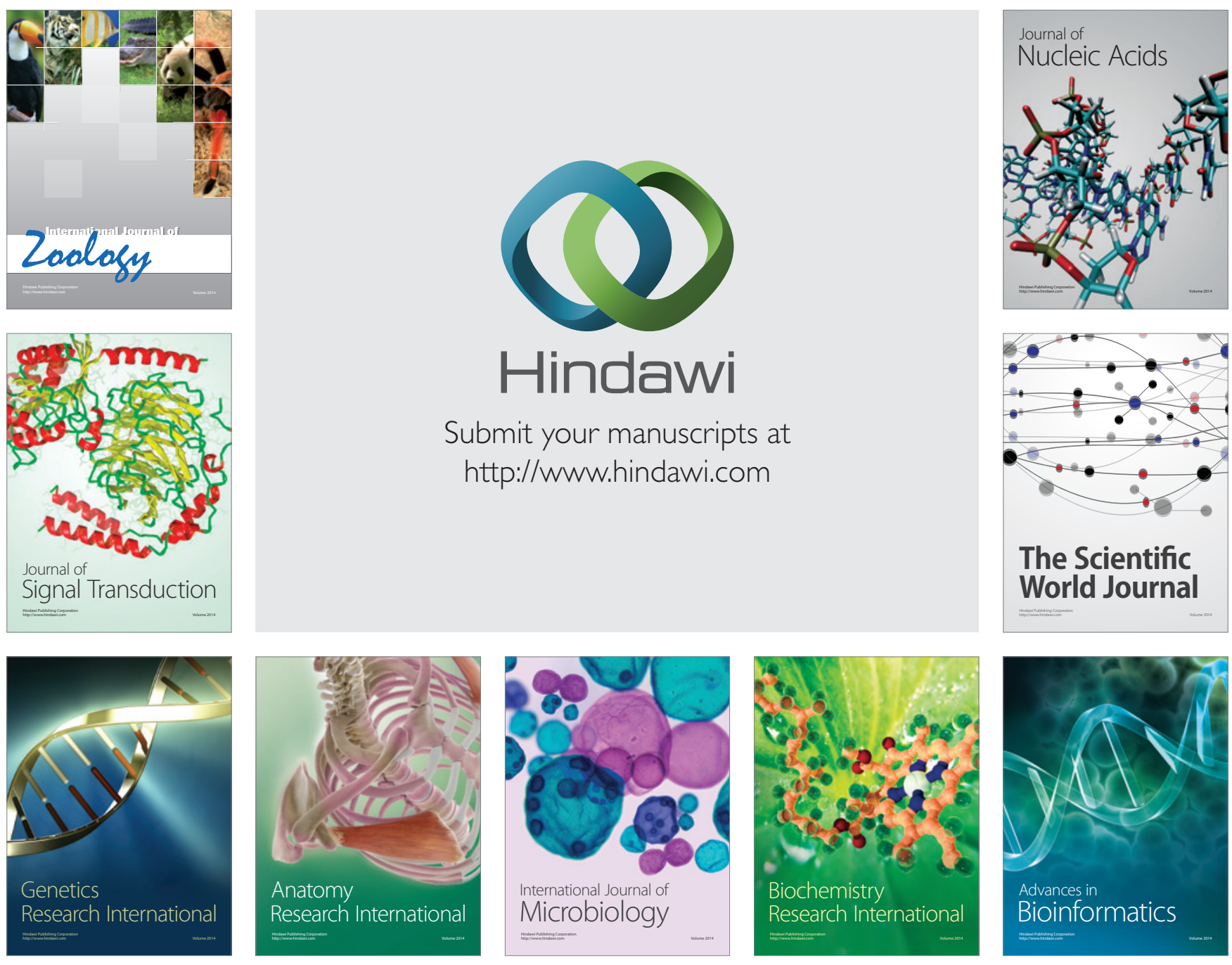

The Scientific World Journal
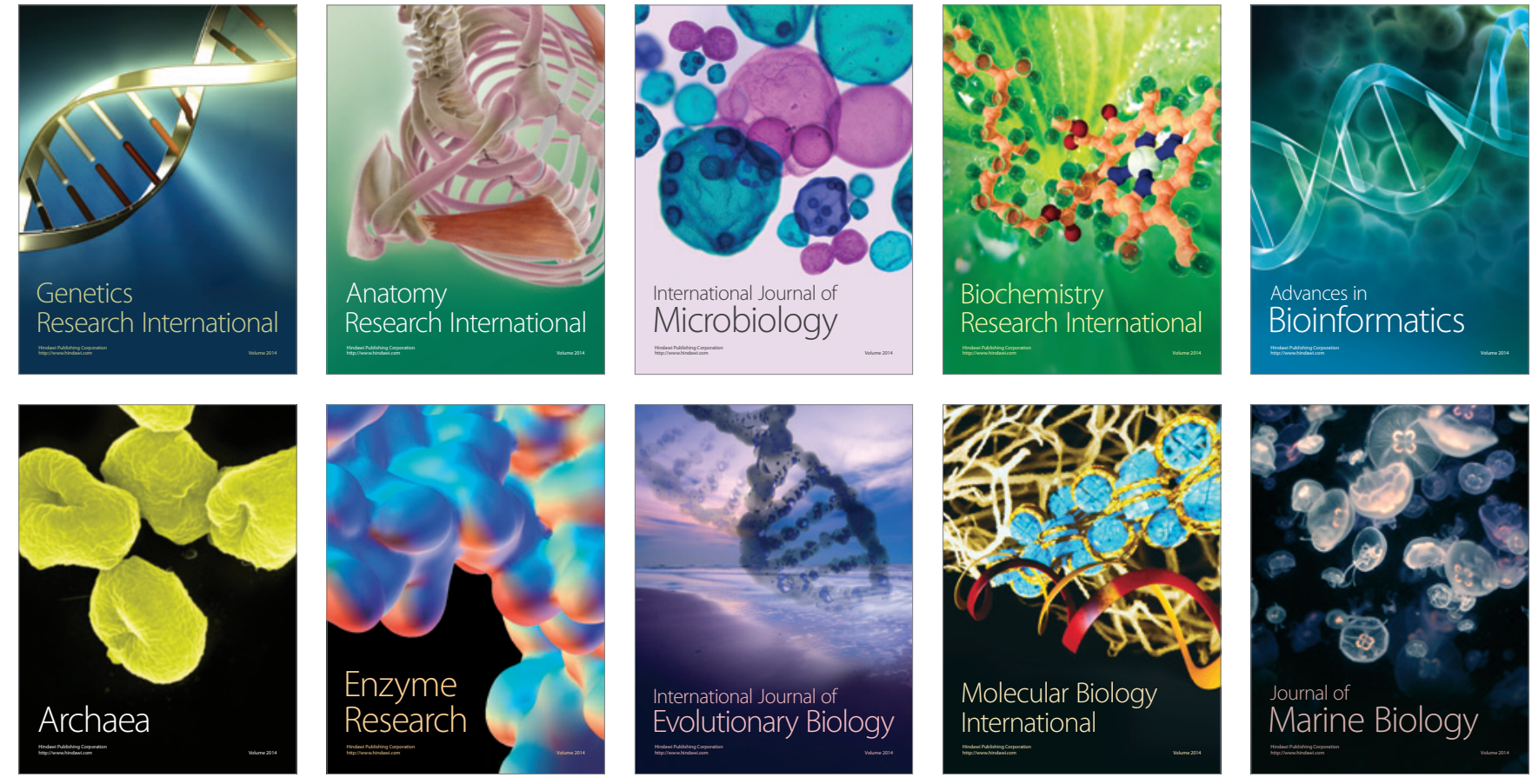